\title{
Dietary luteolin attenuates chronic liver injury induced by mercuric chloride via the Nrf2/NF-KB/P53 signaling pathway in rats
}

\author{
Haili Zhang ${ }^{1}$, Xiao Tan ${ }^{1}$, Daqian Yang ${ }^{1}$, Jingjing Lu ${ }^{1}$, Biying Liu ${ }^{1}$, Ruiqi Baiyun ${ }^{1}$ and \\ Zhigang Zhang ${ }^{1}$ \\ ${ }^{1}$ College of Veterinary Medicine, Northeast Agricultural University, Harbin, 150030, China
}

Correspondence to: Zhigang Zhang, email: zhangzhigang@neau.edu.cn

Keywords: luteolin, $\mathrm{HgCl}_{2}$, hepatotoxicity, Nrf2, NF-KB

Received: January 06, 2017 Accepted: April 11, $2017 \quad$ Published: April 21, 2017

Copyright: Zhang et al. This is an open-access article distributed under the terms of the Creative Commons Attribution License 3.0 (CC BY 3.0), which permits unrestricted use, distribution, and reproduction in any medium, provided the original author and source are credited.

\section{ABSTRACT}

Mercury exposure is a common cause of metal poisoning which is biotransformed to highly toxic metabolites thus eliciting biochemical alterations and oxidative stress. Luteolin, a phenolic compound found in many natural products, has multiple biological functions. Our study was aimed to explore the biological effects of luteolin in a liver injury model induced in rats by mercuric chloride $\left(\mathrm{HgCl}_{2}\right)$. Criteria for injury included liver enzyme, glutathione and malondialdehyde levels, histopathology, TUNEL assay, hepatocyte viability and reactive oxygen species levels. The results showed that luteolin protected against $\mathrm{HgCl}_{2}$-induced liver injury. Luteolin increased total nuclear factor-erythroid-2-related factor 2 ( $\mathrm{Nrf2}$ ) levels in the presence of $\mathrm{HgCl}_{2}$. Upregulation of its downstream factors, heme oxygenase-1 and NAD(P)H quinone oxidoreductase 1 , was also observed. This suggested that protection by luteolin against $\mathrm{HgCl}_{2}$-induced liver injury involved $\mathrm{Nrf2}$ pathway activation. Luteolin also decreased expression of nuclear factor-kB (NF-kB) and $\mathrm{P} 53 . \mathrm{HgCl}_{2}$ exposure led to increased $\mathrm{Bcl}$-associated $X$ protein (BaX), and decreased $\mathrm{Bcl}-2$-related protein long form of $\mathrm{Bcl}-\mathrm{X}(\mathrm{BCl}-\mathrm{XL})$ and B-cell leukemia/lymphoma-2 (Bcl-2) expression, leading to an increased Bax/ $\mathrm{Bcl}-2$ ratio. Taken together, our data suggested that decreasing oxidative stress is a protective mechanism of luteolin against development of $\mathbf{H g C l 2}$-induced liver injury, through the Nrf2/NF-KB/P53 signaling pathway in rats.

\section{INTRODUCTION}

Mercury, in the inorganic form mercuric chloride $\left(\mathrm{HgCl}_{2}\right)$, is the third most dangerous heavy metal and metalloid element, after arsenic and lead, according to the Agency for Toxic Substance and Disease Registry [1]. Although mercury has long been considered a toxic metal, it still has numerous important industrial uses and poisoning from occupational exposure and environmental pollution continues to be a concern [2]. In several in vitro and in vivo studies, damaging effects induced by mercury were related to adverse health impacts including cancer, neurological disorders and cardiovascular diseases [3-4]. Among organs, the liver is the major site for handling toxins, with a central role in physiological metabolism and various detoxification reactions. Primary murine hepatocytes are frequently used as a model for investigating the toxicity and protective mechanisms associated with various toxins. Based on available experimental data, it is a reasonable hypothesis that mercury toxicity involves oxidative stress, inflammation and apoptosis.

In previous reports, treatments for mercury exposure frequently included the dithiol chelators, meso-2,3-dimercaptosuccinic acid (DMSA) and 2,3-dimercaptopropanesulfonic acid (DMPS), which were shown to increase mercury excretion and relieve symptoms [5]. However, these drugs have an appreciable risk of side effects [6]. We previously described remarkable effects of some natural products on prevention and treatment of arsenic poisoning [7-9]. Therefore, as rich sources of pharmaceutical compounds with low toxicity, such natural products might lead to discovery of new drugs for treating mercury poisoning.

Luteolin (Lut, 3', 4', 5, 7-tetrahydroxyflavone), a key member of the flavones, is a naturally occurring 
polyphenolic compound, abundant in vegetables, fruits and natural Chinese herbal medicines such as celery, grapes and peppermint. In current research, antioxidant activity generally measured by free radical scavenging assays [10-12]. Luteolin exhibited a number of biological effects, including anti-inflammatory and anti-oxidative properties, as well as anti-proliferative activities against various cancer cells [13-15]. However, to our knowledge, there have been no systematic empirical reports addressing the impact of luteolin on $\mathrm{HgCl}_{2}$-induced chronic hepatotoxicity.

Based on this background, our study aimed to evaluate liver toxicity of $\mathrm{HgCl}_{2}$ in rats, including serum biochemical parameters, oxidative stress indices and histopathologic alterations. A further goal was to define the detailed mechanisms of luteolin's action against chronic mercury intoxication in rats.

\section{RESULTS}

\section{Hematological analysis}

Effects of $\mathrm{HgCl}_{2}$ and/or luteolin treatment on various hematological attributes are summarized in Table 1.

Values for erythrocytes, hematocrit and hemoglobin were close to control values in rats administered only luteolin. In contrast, these parameters were significantly decreased in the $\mathrm{HgCl}_{2}$-treated group, compared with other groups. These $\mathrm{HgCl}_{2}$-induced decreases were prevented in rats also administered luteolin.

Mean corpuscular volume (MCV), mean corpuscular hemoglobin $(\mathrm{MCH})$ and mean corpuscular hemoglobin concentration (MCHC) were not significantly altered by the treatments.

Meanwhile, compared with the control group, leukocyte counts were significantly increased and platelet counts significantly decreased in the $\mathrm{HgCl}_{2}$-treated group and luteolin administration prevented this change.

\section{Assessment of liver function markers}

Blood biochemistry was performed to evaluate the potential hepatotoxicity of $\mathrm{HgCl}_{2}$. Aspartate transaminase
(AST) and alanine aminotransferase (ALT) are regarded as the useful markers of liver injury. Figure 1A shows that AST levels were significantly increased in the $\mathrm{HgCl}_{2}$-treated group. Similar results were seen with ALT (Figure 1B), indicating that $\mathrm{HgCl}_{2}$ induced liver injury. Luteolin administration in the $\mathrm{HgCl}_{2}$-treated rats led to significantly decreased activities of the two liver enzymes, compared with those treated with $\mathrm{HgCl}_{2}$ alone.

\section{Luteolin decreased oxidative stress induced by $\mathrm{HgCl}_{2}$ in the liver}

Various parameters relating to redox status were monitored in rats after treatment with $\mathrm{HgCl}_{2}$, in the presence or absence of luteolin. The results are shown in Figure 2.

Malondialdehyde (MDA) is a marker for oxidative lipid damage. MDA levels in livers of the $\mathrm{HgCl}_{2}$ group were greater than in the control group. Treatment with luteolin decreased liver MDA levels in rats subsequently treated with $\mathrm{HgCl}_{2}$ (Figure 2A).

In Figure $2 \mathrm{~B}$ and $2 \mathrm{C}$, the $\mathrm{HgCl}_{2}$-treated group had decreased the reduced glutathione (GSH), as well as a decreased GSH/glutathione disulfide (GSSG) ratio, compared with the control group. These effects were attenuated in the group receiving combined treatment with luteolin and $\mathrm{HgCl}_{2}$.

\section{Histopathological examination}

We compared the histological structure among each groups using hematoxylin and eosin $(\mathrm{H} \& \mathrm{E})$. In the control group, the cross-section showed hepatocytes arranged radically surrounding the central vein (Figure 3A). There were no abnormalities or histological changes observed in the livers of luteolin-treated group as illustrated (Figure $3 \mathrm{~B}$ ). $\mathrm{HgCl}_{2}$ administered group showed evident liver injury, which had severe hepatic necrosis, swelling, disappearing, and disarranged structure of hepatic lobules (Figure 3C). These pathological changes were attenuated in the group receiving combined treatment with luteolin and $\mathrm{HgCl}_{2}$, but congestion spaces and inflammatory cell infiltrating were still present (Figure 3D).
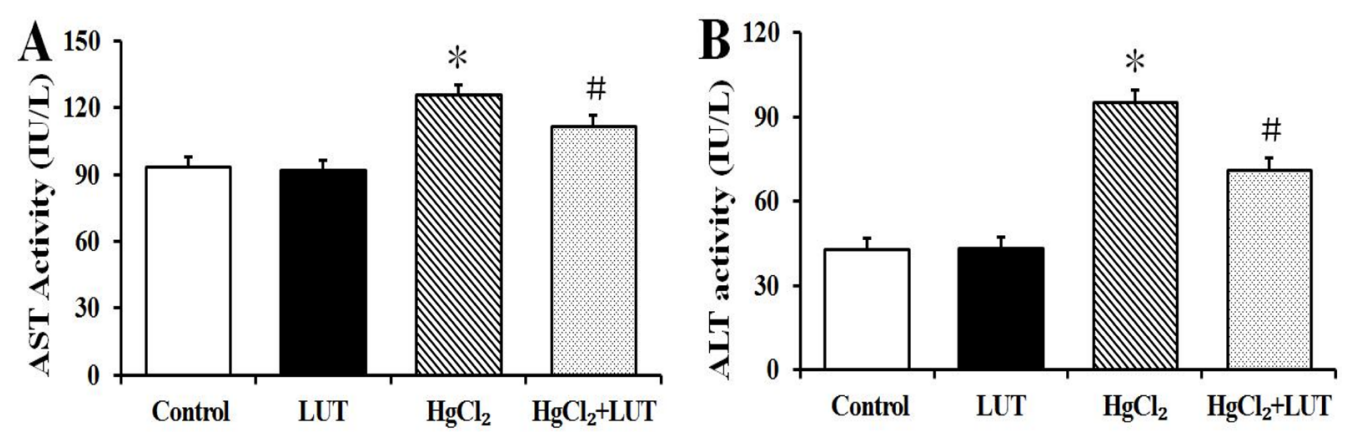

Figure 1: (A and B) illustrate AST and ALT activities respectively in normal and experimental groups of rats. $\mathrm{HgCl}_{2}$ administration increased ALP and ALT levels compared to the normal, while treatment with luteolin significantly restored this change. Data are expressed as means $\pm \operatorname{SEM}(n=8)$. ${ }^{*} P<0.05$ compared to the control group; ${ }^{\sharp} P<0.05$ compared to $\mathrm{HgCl}_{2}$-treated group. 
Table 1: Effects of the luteolin on erythrocytes, hematocrit, hemoglobin, MCH, MCHC, MCV, platelets and leuko cyte values of rats exposed to $\mathrm{HgCl}_{2}$

\begin{tabular}{ccccc}
\hline & Control & LUT & $\mathbf{H g C l}_{2}$ & $\mathbf{H g C l}_{2}+\mathbf{L U T}$ \\
\hline Erythrocyte $\left(\times \mathbf{1 0}^{6} / \mathbf{m l}\right)$ & $8.07 \pm 0.93$ & $7.70 \pm 0.80$ & $6.38 \pm 0.75^{*}$ & $7.37 \pm 1.03^{\#}$ \\
Hemoglobin $(\mathbf{g} / \mathbf{d l})$ & $156.50 \pm 12.56$ & $156.25 \pm 12.00$ & $131.00 \pm 11.44^{*}$ & $144.38 \pm 12.15^{\#}$ \\
& $40.64 \pm 3.01$ & $38.89 \pm 2.78$ & $30.29 \pm 3.01^{*}$ & $34.76 \pm 2.33^{\#}$ \\
Hematocrit $(\mathbf{\%})$ & $19.23 \pm 1.46$ & $19.96 \pm 1.23$ & $19.71 \pm 1.97$ & $19.96 \pm 2.67$ \\
MCH (pg) & $398.50 \pm 25.17$ & $427.13 \pm 22.48$ & $404.63 \pm 34.68$ & $409.50 \pm 36.75$ \\
MCHC (g/dl) & $48.79 \pm 2.36$ & $47.81 \pm 2.29$ & $48.81 \pm 1.39$ & $47.70 \pm 1.08$ \\
MCV (fl) & $445.50 \pm 42.30$ & $435.50 \pm 40.17$ & $334.88 \pm 34.96^{*}$ & $383.94 \pm 23.34^{\#}$ \\
Platelets $(\times \mathbf{1 0} / \mathbf{m l})$ & $8.48 \pm 1.29$ & $8.03 \pm 0.96$ & $11.90 \pm 1.17^{*}$ & $8.07 \pm 1.09^{\#}$ \\
\hline Leukocyte $(\times \mathbf{1 0} / \mathbf{m l})$ & & &
\end{tabular}

Data are expressed as means $\pm \operatorname{SEM}(n=8) .{ }^{*} P<0.05$ compared to the control group; ${ }^{\sharp} P<0.05$ compared to $\mathrm{HgCl}_{2}$-treated group.

\section{Luteolin inhibited hepatocyte apoptosis}

To determine whether the heptoprotective effects of luteolin could be detected histopathologically, we employed terminal deoxynucleotidyl transferase-mediated dUTP nick end labeling (TUNEL) staining to examine apoptotic cells in the liver tissue (Figure 4). There were few TUNELpositive cells in the control group, while $\mathrm{HgCl}_{2}$ induced an apoptotic index of approximate $25.73 \%$. There was no difference in apoptosis indexes in the control group and the luteolin treated group. $\mathrm{In} \mathrm{HgCl}_{2}$ treated rats, luteolin significantly decreased the apoptotic index to $14.13 \%$.

\section{Luteolin prevented cytotoxicity and formation of reactive oxygen species (ROS) generation induced by $\mathrm{HgCl}_{2}$ in vitro}

We investigated whether luteolin could prevent $\mathrm{HgCl}_{2}$-induced hepatotoxicity in vitro. As shown in Figure $5 \mathrm{~A}$, hepatocytes incubated with $5 \mu \mathrm{M} \mathrm{HgCl}_{2}$ had decreased cell viability and this was prevented by luteolin.

We examined effects of luteolin on intracellular ROS production by a fluorescence based method. Hepatocytes were incubated with DCFH-DA and analyzed by fluorescence microscopy. As shown in Figure $5 \mathrm{~B}, \mathrm{HgCl}_{2}$ treatment significantly increased intracellular ROS levels, while this effect was lower in the presence of luteolin. There was no significant difference in fluorescence between the control and luteolin-treated groups.

\section{Effects of luteolin on forkhead box $\mathrm{O3}$ (FoxO3) gene expression}

RT-PCR results indicated that FoxO3 mRNA was down-regulated after $\mathrm{HgCl}_{2}$-induced hepatotoxicity.
Additionally, luteolin administration enhanced mRNA expression of FoxO3 compared with the $\mathrm{HgCl}_{2}$-treated group (Figure 6).

\section{Effects of luteolin on total nuclear factor-} erythroid-2-related factor 2 (Nrf2) protein and Nrf2-related protein levels in the liver

To investigate effects of luteolin on Nrf2, the primary transcription factor regulating oxidative stress, we measured Nrf2 activation.

As shown in Figure 7A and 7B, there was substantial down-regulation of $\mathrm{Nrf2}$ protein expression in the $\mathrm{HgCl}_{2}$ treated group, compared with rats receiving no treatment or only luteolin. In addition, Nrf2 protein expression was increased by treatment with both $\mathrm{HgCl}_{2}$ and luteolin.

$\mathrm{NAD}(\mathrm{P}) \mathrm{H}$ quinone oxidoreductase 1 (NQO1) and heme oxygenase-1 (HO-1) are important cellular antioxidant enzymes, as well as being Nrf2-regulated genes. $\mathrm{HgCl}_{2}$ decreased $\mathrm{NQO} 1$ and $\mathrm{HO}-1$ protein expression, while luteolin significantly increased levels of both proteins when administered after the $\mathrm{HgCl}_{2}$ (Figure 7A, 7C and 7D).

\section{Effects of luteolin on the mitochondrial pathway of apoptosis}

It is known that B-cell leukemia/lymphoma-2 (Bcl-2) family proteins are upstream regulators of mitochondrial events and play critical roles in mitochondria-mediated apoptosis. The Bcl-associated $\mathrm{X}$ protein $(\mathrm{Bax}) / \mathrm{Bcl}-2$ ratio is of particular interest because of its significance in mitochondria-mediated cellular functions. $\mathrm{HgCl}_{2}$ caused a decrease and increase in expression of Bcl-2 and Bax, respectively. This led to 

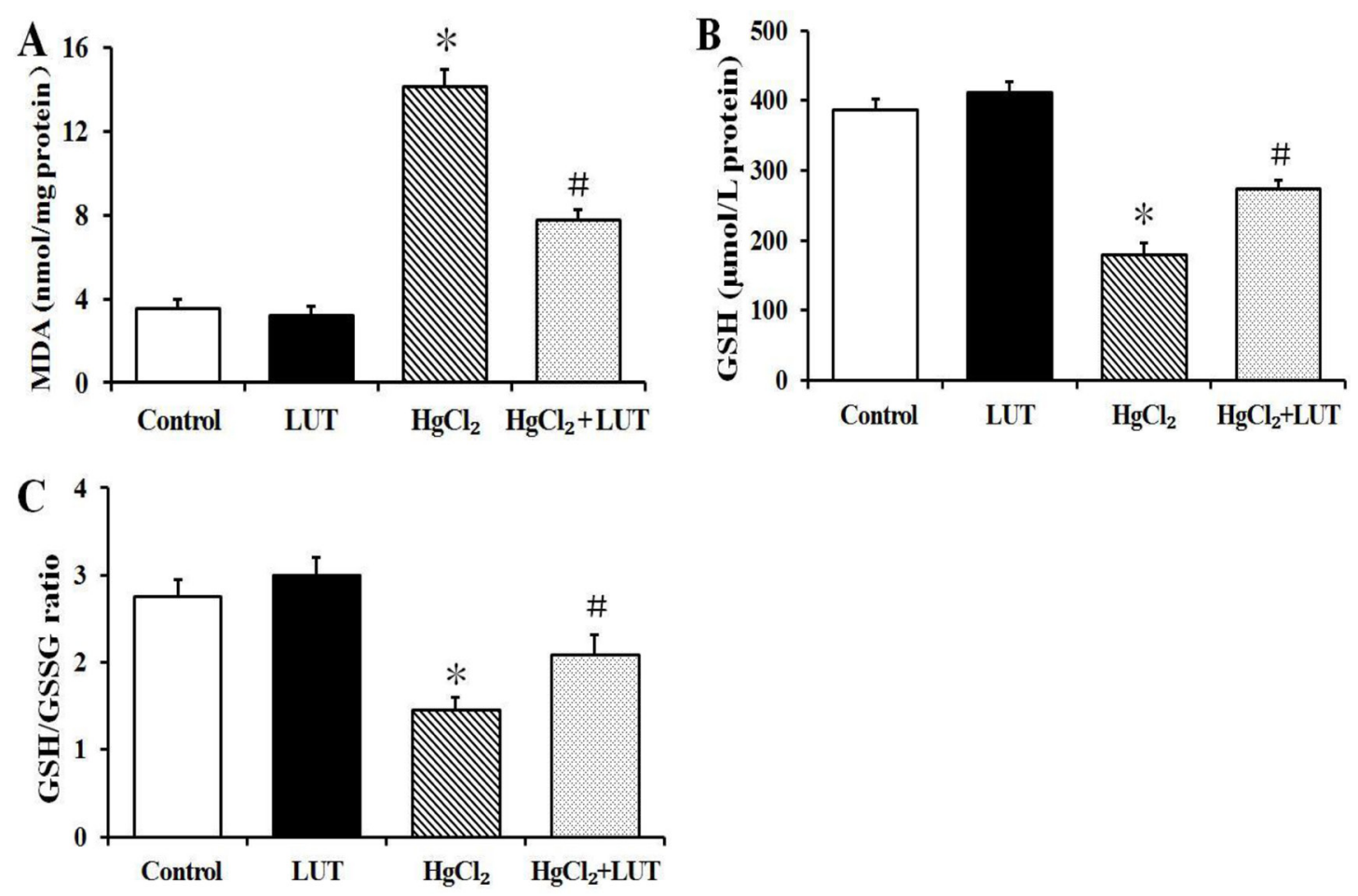

Figure 2: Effects of luteolin given to rats prior to $\mathrm{HgCl}_{2}$ administration on concentration of $\mathrm{MDA}$ and GSH in liver tissue. Results of MDA activity (A) GSH activity (B) and GSH/GSSG ratio (C) in the liver are expressed as means \pm SEM $(n=8)$. ${ }^{*} P<0.05$ compared to the control group; ${ }^{\#} P<0.05$ compared to $\mathrm{HgCl}_{2}$-treated group.
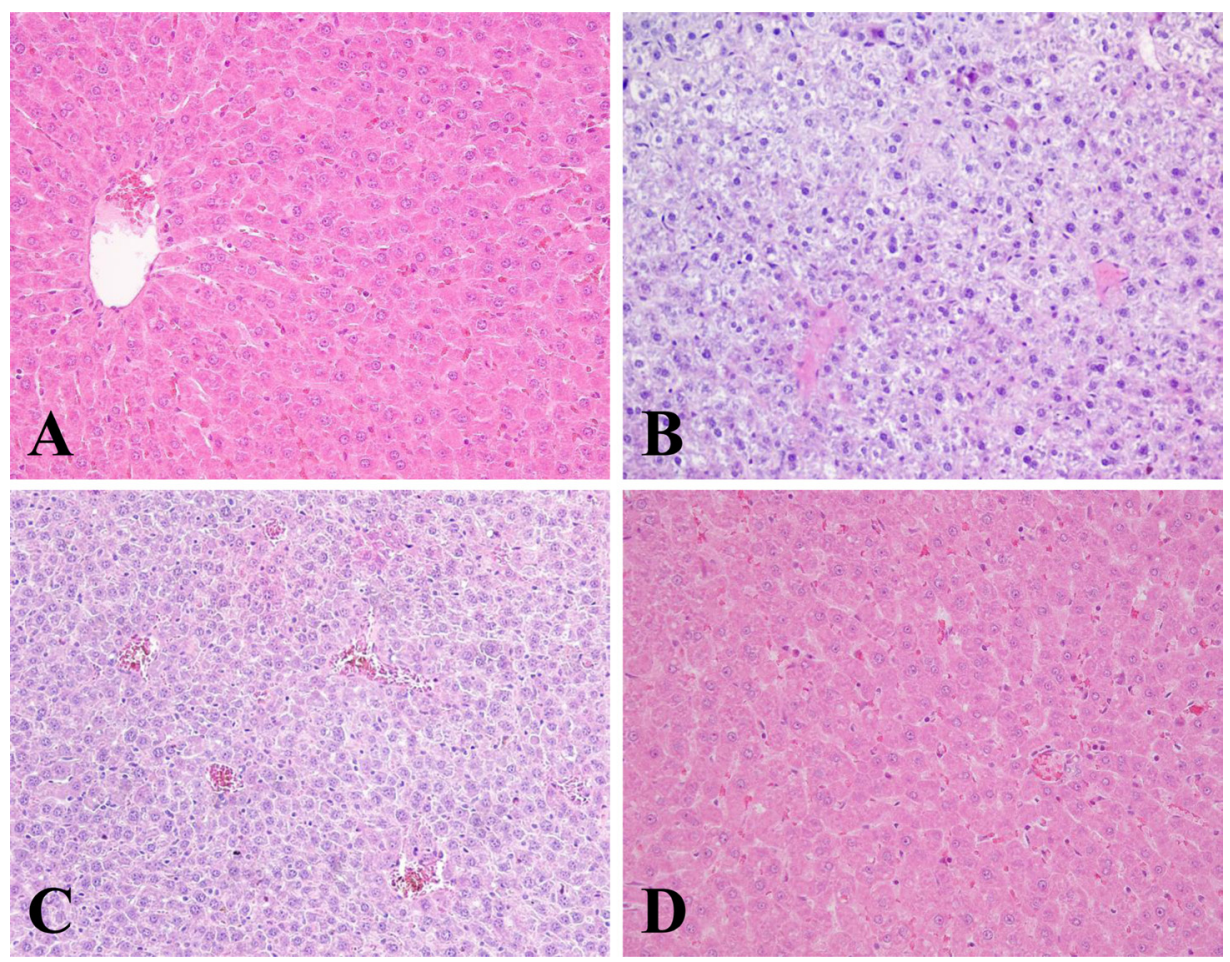

Figure 3: The histological of livers changed after different treatments. Tissues were fixed in $4 \%$ paraformaldehyde, embedded in paraffin, and stained with H\&E. Typical images were chosen from each experimental group (original magnification 200×): (A) control group. (B) Rats treated with luteolin. (C) Rats treated with $\mathrm{HgCl}_{2}$. (D) Rats treated with the luteolin and $\mathrm{HgCl}_{2}$. 


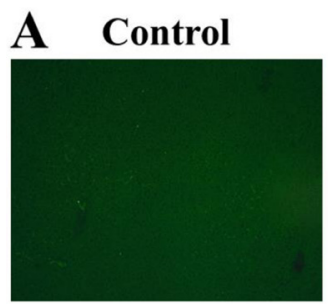

$\mathrm{HgCl}_{2}$

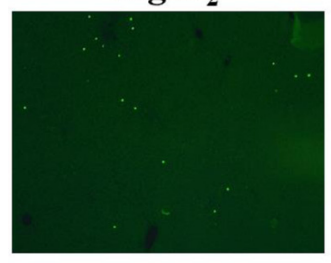

LUT
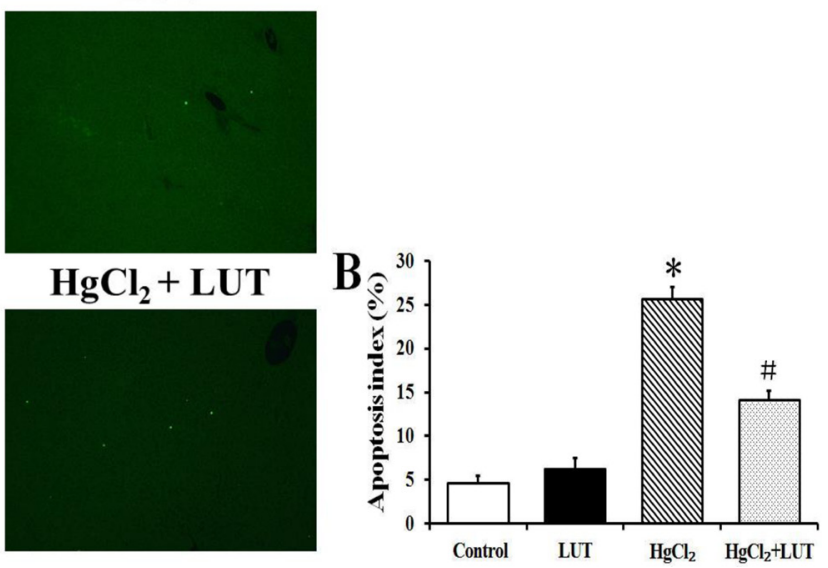

Figure 4: Apoptosis index was determined using TUNEL assays. (A) Representative photographs of TUNEL staining in control, LUT, $\mathrm{HgCl}_{2}$ and $\mathrm{HgCl}_{2}+$ LUT groups. Scale bar $=20 \mu \mathrm{m}$. (B) Quantitative analysis of TUNEL-positive cells. Luteolin treatment significantly decreased the percentage of hepatocyte apoptosis after $\mathrm{HgCl}_{2}$ treatment. Data are expressed as means \pm SEM $(n=8)$. $* P<0.05$ compared to rhe control group; ${ }^{*} P<0.05$ compared to $\mathrm{HgCl}_{2}$-treated group.
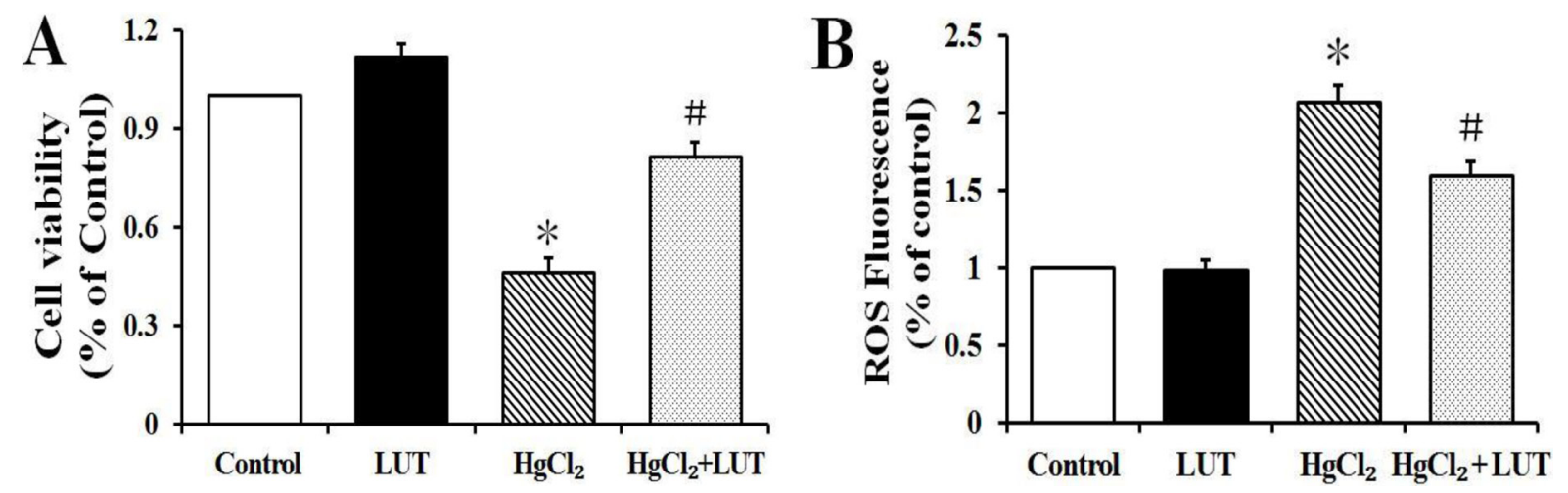

Figure 5: (A) The survival cells were determined by CCK-8 assay. (B) The levels of intracellular ROS in hepatocytes were determined by DCF-DA as described in Material and Methods. The results are expressed in percentage of control and presented as the means \pm SEM $(n=6) . * P<0.05$ compared to the control group; ${ }^{\sharp} P<0.05$ compared to $\mathrm{HgCl}_{2}$-treated group.

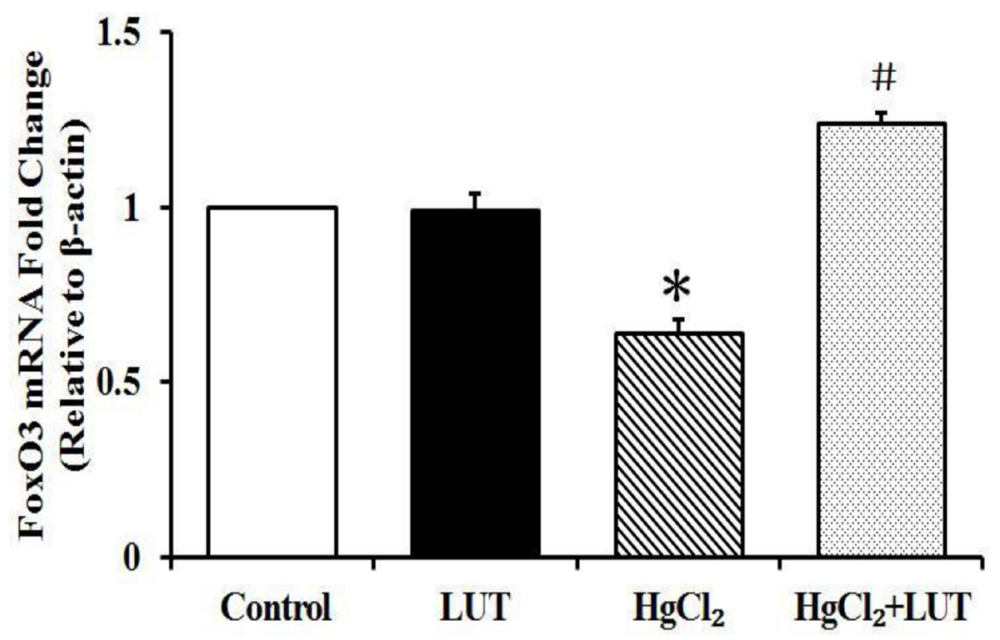

Figure 6: RT-PCR analysis of FoxO3 gene expression levels after $\mathrm{HgCl} 2$ treatment and/or luteolin and $\beta$-actin was used as an internal control. Data are expressed as means $\pm \operatorname{SEM}(n=4) .{ }^{*} P<0.05$ compared to the control group; ${ }^{\#} P<0.05$ compared to $\mathrm{HgCl}_{2}$-treated group. 
an increased ratio of Bax to Bcl-2 and, subsequently, to cell apoptosis through a mitochondria-dependent pathway (Figure 8).

\section{Effects of luteolin on P53, nuclear factor- $\kappa B$ $(\mathrm{NF}-\kappa \mathrm{B})$ and tumor necrosis factor $\alpha(\mathrm{TNF}-\alpha)$ protein levels}

P53 proteins levels were increased by $\mathrm{HgCl}_{2}$ and this effect was suppressed by luteolin treatment (Figure 9A and 9B). In $\mathrm{HgCl}_{2}$-treated rats, $\mathrm{HgCl}_{2}$ caused an increase in expression of $\mathrm{NF}-\kappa \mathrm{B}$ than in the control group. Conversely, treatment with luteolin decrease NF- $\kappa \mathrm{B}$ protein expression (Figure $9 \mathrm{C}$ ). In addition, TNF- $\alpha$ expression followed the same trend as NF- $\kappa \mathrm{B}$ (Figure 9D).

\section{Mercury accumulation in the livers of rats}

Effects of luteolin on mercury accumulation in the liver were shown in Figure 10. Treatment with $\mathrm{HgCl}_{2}$ alone led to significantly increased mercury concentrations, compared with the control group. Treatment with luteolin to mercury exposure significantly decreased mercury accumulation in the liver tissue.

\section{DISCUSSION}

In vertebrate organisms, erythrocytes are the principal means for delivering oxygen $\left(\mathrm{O}_{2}\right)$ to body tissues, via blood flowing through the circulatory system. Hemoglobin is the iron-containing oxygen-transport metalloprotein in red blood cells and the hematocrit is the volume percentage $(\%)$ of erythrocyte in blood [16]. We observed decreases in these two indexes, indicating that $\mathrm{HgCl}_{2}$ interrupted the supply of $\mathrm{O}_{2}$ to the body, inducing anemia in the rats. There was an increase in leukocyte counts in rats exposed to $\mathrm{HgCl}_{2}$ and administration of luteolin was decrease. Platelet counts in rats exposed to $\mathrm{HgCl}_{2}$ were decreased significantly compared with the control group. However, in this study, mercury exposure had no significant effects on $\mathrm{MCV}, \mathrm{MCHC}$ or $\mathrm{MCH}$ values. This might have been because of the dose and duration of administration used in our exposure protocol.

The amount of a metal accumulated at the target organ has been described as causing its toxicity [17]. According to Flora et al. [18], mercury toxicity can cause free radical generation in many tissues, especially the liver. AST and ALT are important markers for hepatocellular damage, as confirmed by Abdel-Moneim et al. [19]. In our study, we showed that treatment with luteolin significantly decreased mercury accumulation in the liver tissues. Increased serum AST and ALT activities have been attributed to the damage of liver structural. The increased of AST and ALT were confirmed by histological examination. The changes observed primarily included hepatocellular necrosis or apoptosis, inflammatory cell infiltration and other histological manifestations, all effects consistent with other reports [20]. Therefore, our findings indicated that the presence of luteolin led to improvements in $\mathrm{HgCl}_{2}$-induced organ dysfunction.

Oxidative stress is induced when cellular levels of ROS exceed antioxidant response capacity. This results in perturbation of the cellular redox state by producing peroxides and free radicals that damage lipids, DNA and
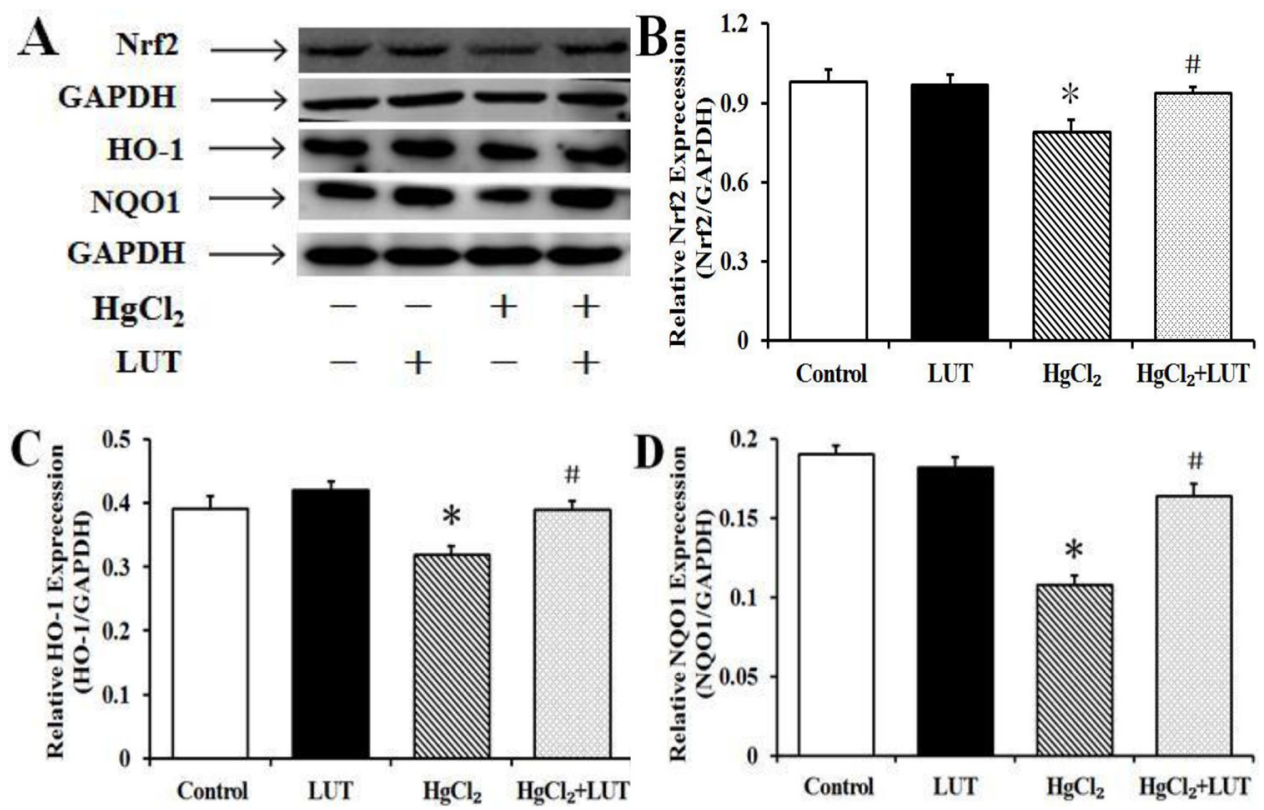

Figure 7: Treatment with luteolin activated the $\mathrm{Nrf2}$ pathway and protected the liver against $\mathrm{HgCl}_{2}$-induced injury. (A) The protein levels of Nrf2, HO-1 and NQO1. (B, C and D) Quantifed protein levels were shown. GAPDH was used as an internal control. Data are expressed as means $\pm \operatorname{SEM}(n=4)$. ${ }^{*} P<0.05$ compared to the control group; ${ }^{\sharp} P<0.05$ compared to the $\mathrm{HgCl}_{2}$-treated group. 
protein [21-23]. We observed increased ROS production in vitro in hepatocytes exposed to $\mathrm{HgCl}_{2}$. High levels of ROS are known to induce lipid peroxidation, detectable by increased MDA levels [24]. $\mathrm{HgCl}_{2}$ manifests its toxicity by increasing ROS and binding to thiol groups in several proteins and peptides, including GSH and many of the antioxidant enzymes [25]. As shown in Figure $2 \mathrm{~B}$ and $2 \mathrm{C}, \mathrm{HgCl}_{2}$ treatment caused decreases in both GSH level and GSH/GSSG ratio. All our data indicated that luteolin eliminated ROS and prevented the $\mathrm{HgCl}_{2}$-induced decrease in antioxidant defenses.

Inflammation is often associated with an overproduction of ROS and is considered important for $\mathrm{HgCl}_{2}$ induced liver injury. Inflammation is defined as a defense mechanism involving activation, by pro-inflammatory mediators, of $\mathrm{NF}-\kappa \mathrm{B}$ as a primary event. Previous research suggested that TNF- $\alpha$ was crucial in cigarette smoke-induced inflammation [26]. In our study, NF- $\kappa \mathrm{B}$ activation and significant TNF- $\alpha$ upregulation in the livers of rats treated with $\mathrm{HgCl}_{2}$ were substantially attenuated by luteolin (Figure 9). This suggested that attenuation of $\mathrm{HgCl}_{2}$-induced liver injury by luteolin was related to its anti-inflammatory effect.
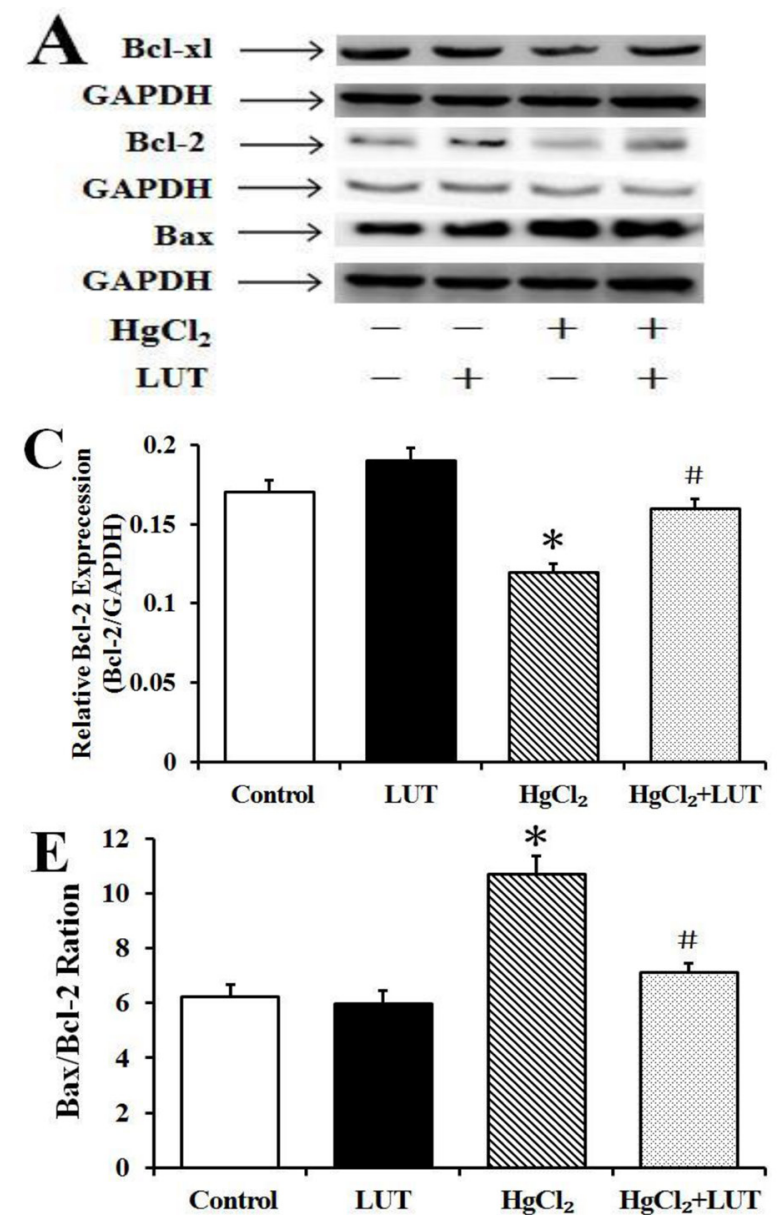

The Bcl-2 family of intracellular proteins are considered key regulators of apoptosis [27]. Our immunoblotting studies demonstrated that $\mathrm{HgCl}_{2}$ downregulated antiapoptotic (Bcl-2 and $\mathrm{Bcl}-\mathrm{xL}$ ) and upregulated proapoptotic (Bax) family members, increasing the $\mathrm{Bax} / \mathrm{Bcl}-2$ ratio in the liver tissue. However, luteolin treatment prevented these changes. In addition, the apoptotic index and cell viability of hepatocytes were determined with TUNEL and CCK-8 assays, respectively (Figure 4 and Figure 5A), with results consistent with observed effects on Bcl-2 family proteins. These findings suggested that luteolin was pivotal in regulating apoptosis, while inhibiting free radical production and oxidative stress-induced cell death.

The mitochondria are crucial in apoptosis. Cytoplasmic P53 was suggested as activating mitochondrial-mediated apoptosis [28] and increased nuclear P53 was shown to indicate decreased apoptosis [29]. FoxO family transcription factors, particularly FoxO3a, are commonly associated with induction of autophagy-related genes [30]. In previous reports, phosphorylated FoxO3a promoted p53 translocation to the cytoplasm and FoxO3a phosphorylated at Thr32 promoted
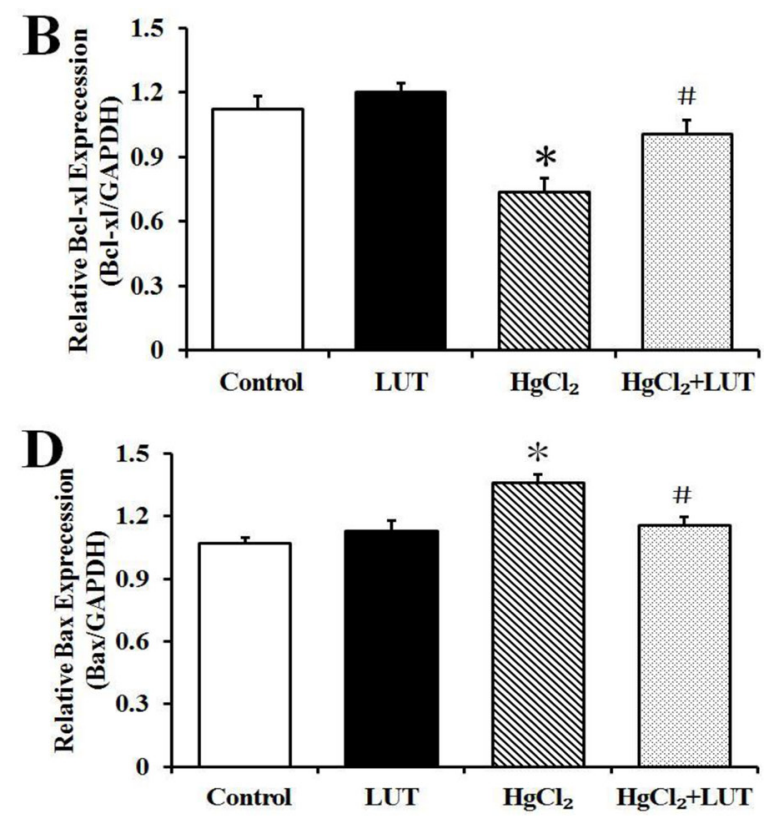

Figure 8: (A) Western blot to evaluate the expression levels of Bcl-xl (B), Bcl-2 (C), Bax (D) and Bax/Bcl-2 ratio (E) in liver tissue and gray value analysis. GAPDH was used as an internal control and data are expressed as means $\pm \operatorname{SEM}(n=4)$. $* P<0.05$ compared to the control group; ${ }^{\#} P<0.05$ compared to $\mathrm{HgCl}_{2}$-treated group. 
FoxO3a export from the nucleus [31]. We observed that luteolin enhanced mRNA levels of FoxO3a transcription factors. Thus, we speculated that luteolin affected regulation of P53 localization by FoxO3a. However, further investigation is needed to elucidate the specific mechanism.

Nrf2, a factor sensing the presence of oxidative stress, regulates transcription of genes encoding for cytoprotective enzymes and other proteins crucial for maintaining cellular homeostasis. Under physiological conditions, the Nrf2 inhibitor, Keap-1, binds and retains Nrf2 in the cytoplasm [32]. Nrf2 is inhibited by binding to its negative regulator Keap1, thus modulating its activity [32]. During oxidative stress, Nrf2 dissociates from Keap1, translocates to the nucleus and activates AREdependent gene expression, including transcription of such target genes as NQO-1 and HO-1 [33-34]. Increased cell death caused by $\mathrm{HgCl}_{2}$ might be attributed to insufficient ROS removal because of a failure in Nrf2 activation. However, we found that luteolin could activate this antioxidant pathway, affecting both Nrf2 protein levels and expression of its target proteins. Therefore, our results suggested that $\mathrm{Nrf} 2$ activation was required for protection of the liver, by luteolin, from $\mathrm{HgCl}_{2}$-mediated cell death.

In conclusion, both in vitro and rat models, our study demonstrated that dietary luteolin attenuated chronic liver injury induced by $\mathrm{HgCl}_{2}$, through regulation of the $\mathrm{Nrf2}$ / NF- $\kappa$ B/P53 signaling pathway (Figure 11). Therefore, luteolin administration may be a novel therapeutic approach for treating inorganic mercury poisoning, although optimizing timing to dose is a key question that must be explored in future studies.

\section{MATERIALS AND METHODS}

\section{Animals}

All procedures used in this study were approved by the Institutional Animal Care and Use Committee of Northeast Agricultural University. Twenty-eight 6-8 weeks old male Wistar rats come from the Experimental Animal Centre of Harbin Veterinary Research Institute of Chinese Academy of Agricultural Sciences (Harbin, China) with the weight ranging from 110 to $130 \mathrm{~g}$. The rats were housed individually in an environmentally controlled room maintained at $24-26^{\circ} \mathrm{C}$, with a $12 \mathrm{~h}$ interval light-dark cycle for 1 week. All rats were provided with water and a balanced diet ad libitum.

\section{Experimental protocol}

Wistar rats were randomly divided into the following 4 groups: control, Lut (purity $>98 \%$, Xi'an Weiao, Shanxi, China), $\mathrm{HgCl}_{2}$ (Beijing Chemical Factory, China) and $\mathrm{HgCl}_{2}+$ Lut groups, 7 rats each group. The rats received $80 \mathrm{mg} / \mathrm{L} \mathrm{HgCl}_{2}$ in their drinking water for 8 weeks. Freshly made $\mathrm{HgCl}_{2}$-containing drinking water
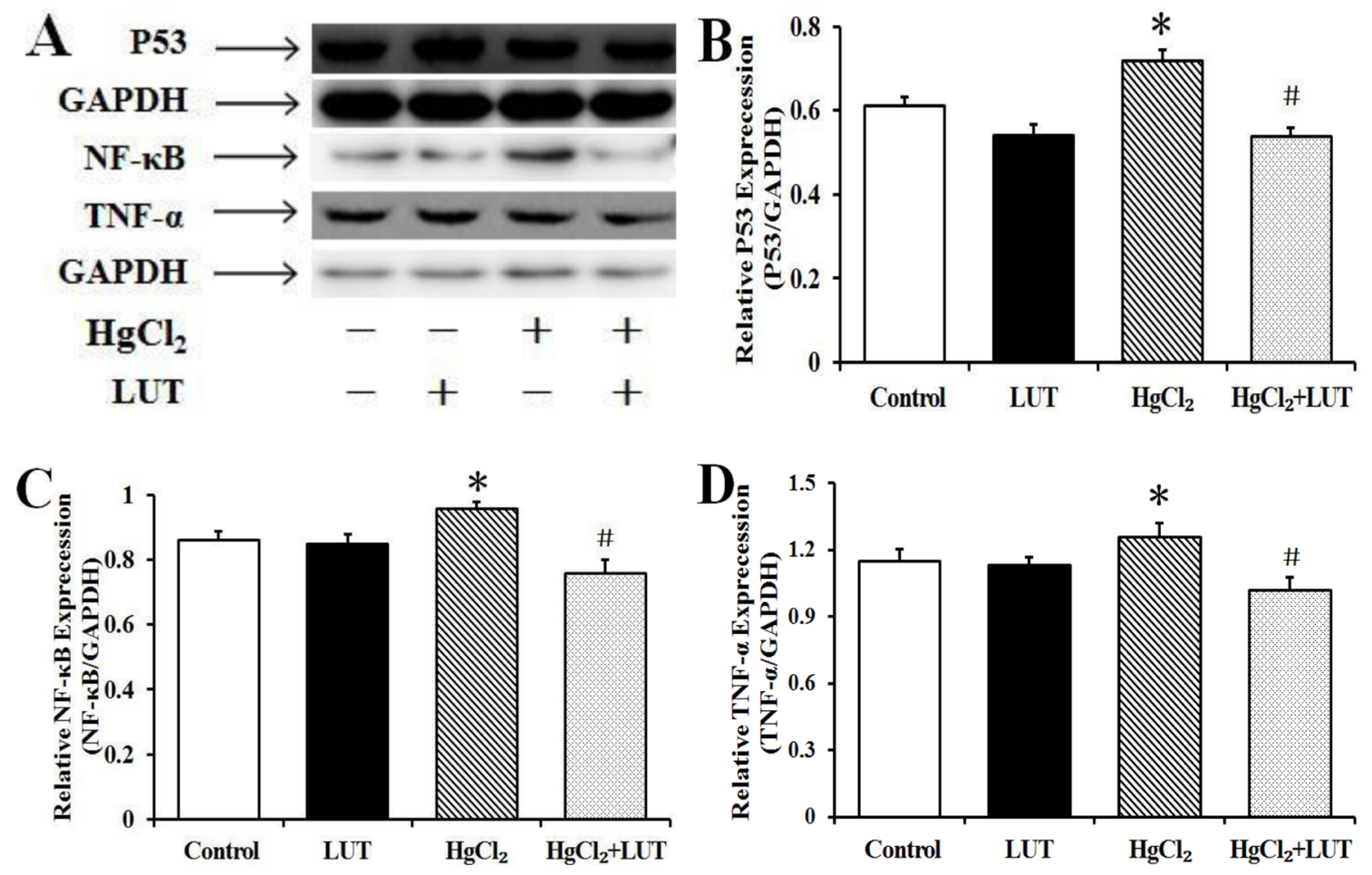

Figure 9: (A) Effects of luteolin on P53, NF- $\kappa \mathrm{B}$ and TNF- $\alpha$ activaties induced by $\mathrm{HgCl}_{2}$ in the liver. These activities were detected by immunoblotting and GAPDH was used as loading control. (B, C and D) Quantifed protein levels were shown. Data are expressed as means $\pm \operatorname{SEM}(n=4) .{ }^{*} P<0.05$ compared to the control group; ${ }^{*} P<0.05$ compared to $\mathrm{HgCl}_{2}$-treated group. 
was provided every day. Luteolin was gavaged to rats once daily for the last 2 weeks at dose levels of $80 \mathrm{mg} / \mathrm{kg}$ in $1 \%$ DMSO, and the daily application volumes of luteolin were calculated based on the most recently recorded body weight of the individual animal. Twenty-four hours after the last feeding, surgery was performed on all rats under anesthesia to obtain the blood and liver tissue samples. For histological and TUNEL analysis, a portion of tissues was immersed in $4 \%$ paraformaldehyde overnight. The rest of samples were immediately frozen in liquid nitrogen and stored at $-80^{\circ} \mathrm{C}$ until use.

\section{Biochemical analysis}

Blood samples were collected from the abdominal aorta into evacuated tubes and immediately centrifuged at $4,000 \mathrm{rpm}$ for $10 \mathrm{~min}$ at $4^{\circ} \mathrm{C}$ to separate serum. Serum ALT and AST activities were determined to assess the

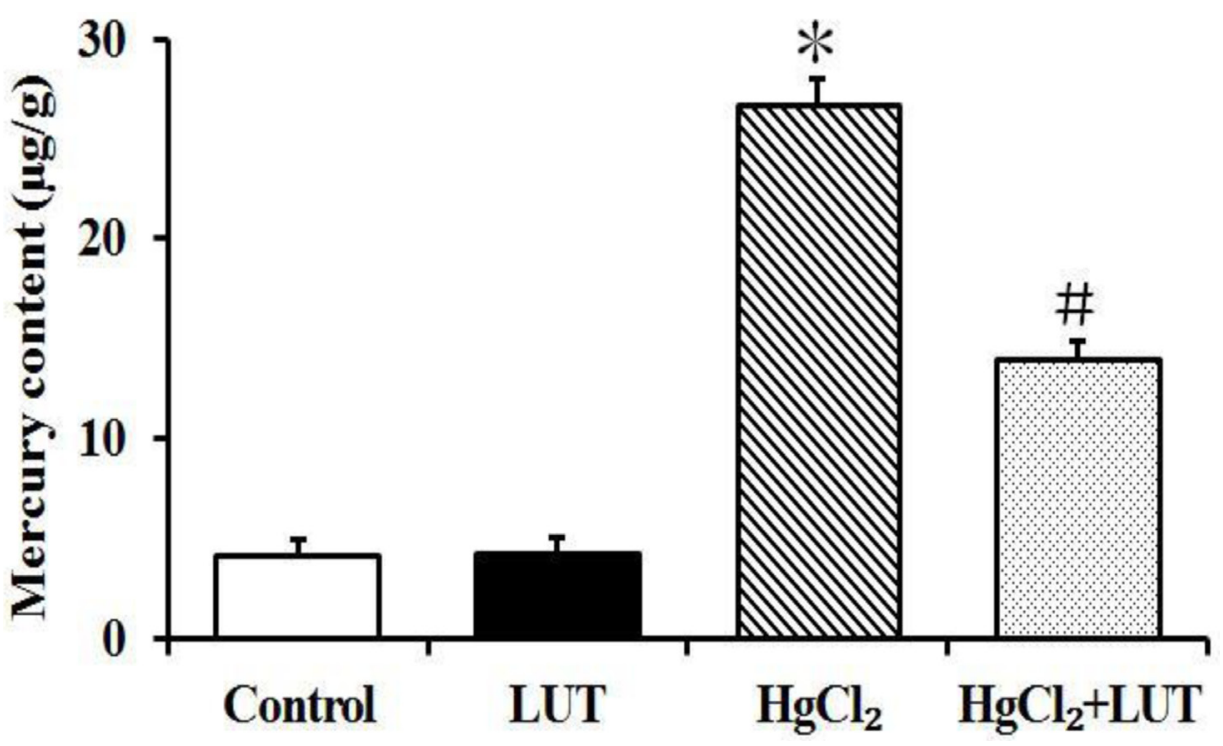

Figure 10: Mercury content analysis was done in the liver and mercury exposed rats as described in materials and methods. Tissues were digested in $\mathrm{HNO}_{3}$, followed by analysis by atomic fluorescence spectrometry. Data are expressed as means $\pm \mathrm{SEM}$ $(n=8) .{ }^{*} P<0.05$ compared to the control group; ${ }^{\sharp} P<0.05$ compared to $\mathrm{HgCl}_{2}$-treated group.

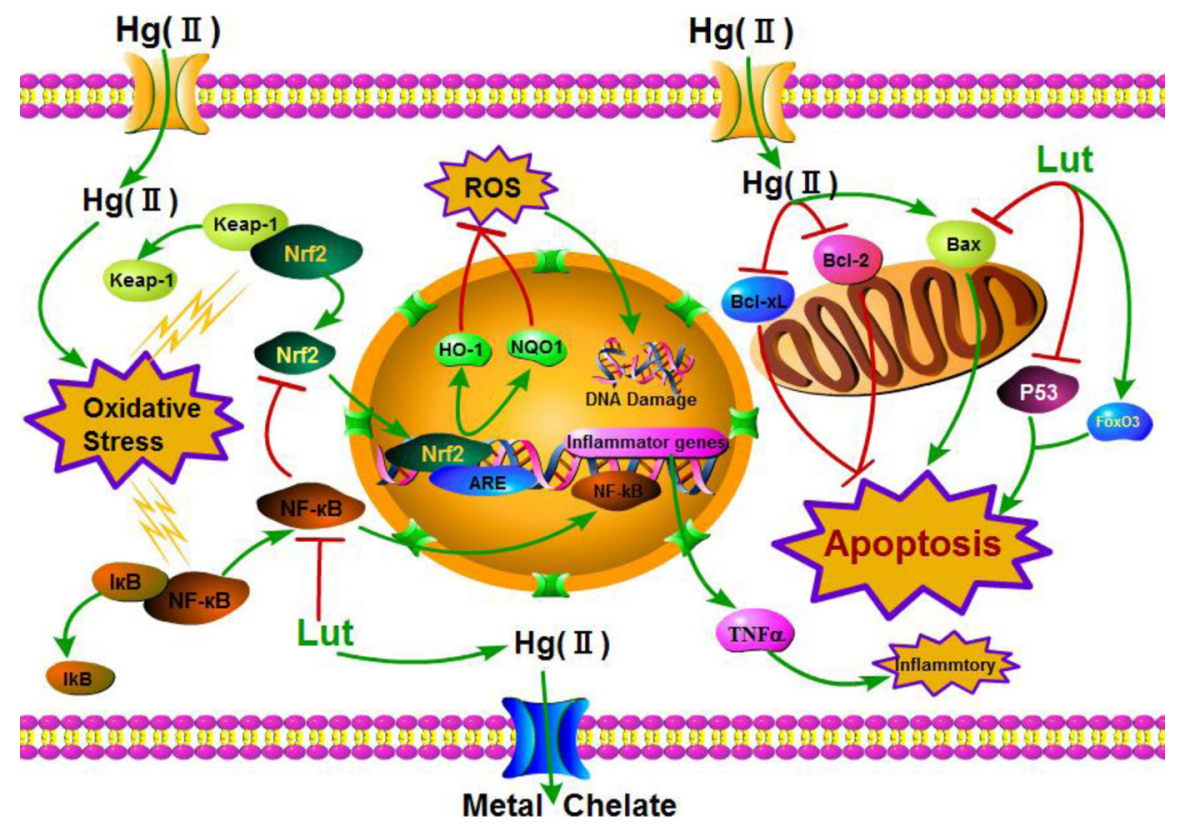

Figure 11: Summary indicating the mechanisms of luteolin attenuated liver injury induced by $\mathrm{HgCl}_{2}$. $\mathrm{Hg}(\mathrm{II})$ promoted ROS formation in cytoplasm inducing oxidative stress, finally led to apoptosis. However, luteolin triggered the activation of NF- $\mathrm{B} / \mathrm{Nrf} 2 /$ P53 signaling pathway and prevented liver injury induced by $\mathrm{Hg}(\mathrm{II})$. Green line denotes stimulatory or inhibitory effect of luteolin, and red line denotes inhibitory effect. 
Table 2: Primers used for real-time PCR1

\begin{tabular}{ccc}
\hline Gene & $\mathbf{5}^{\prime}-\mathbf{3}^{\prime}$ Primer sequence & Product size (bp) \\
\hline FoxO3 - F & GAGTCCATCATCCGTAGC & 438 \\
FoxO3 - R & GAGGGTCAAAGGAAACAA & \\
$\boldsymbol{\beta}$-actin - F & GAGAGGGAAATCGTGCGTGAC & 452 \\
$\boldsymbol{\beta}$-actin - $\mathbf{R}$ & CATCTGCTGGAAGGTGGACA & \\
\hline
\end{tabular}

liver function by an Automatic Biochemical Analyzer (UniCel DxC800, Beckman Coulter, USA).

\section{Determination of parameters associated with oxidative stress in the liver tissues}

Liver tissues were rapidly excised and homogenized in phosphate-buffered saline $(\mathrm{pH} 7.4, \mathrm{w} / \mathrm{v} ; 1 \mathrm{~g}$ tissue with $9 \mathrm{~mL}$ PBS) with an Ultra-Turrax T25 Homogenizer. After centrifugation at $4,000 \mathrm{rpm}$ for $10 \mathrm{~min}$ at $4^{\circ} \mathrm{C}$, the liver samples were used to analyze parameters related to oxidative stress including MDA, GSH and GSSG. These parameters were determined by commercial kits (Jiancheng Bioengineering Institute, Nanjing, China) according to the manufacturer's instructions. The tests were conducted by a spectrophotometer (T60 UV-VIS; Beijing Purkinje General Instruments, Beijing, China).

\section{Histopathological analysis}

For the histological analysis, the liver tissues were removed from $10 \%$ formalin, then embedded in paraffin. Sections with $3 \mu \mathrm{m}$ thick midsections of livers were excised from each group and stained with H\&E. After finishing the routine pathology of H\&E staining, the slides were evaluated by the specific histological alteration of livers under a light microscope (BX-FM, Olympus Corp, Tokyo, Japan).

\section{TUNEL assay}

The apoptotic cells were determined with a TUNEL detection kit (Kaiji, Nanjing, China). For TUNEL assay, coverslips were dealt with $1 \%$ Triton X-100/PBS, and blocked with $3 \% \mathrm{H}_{2} \mathrm{O}_{2} /$ methanol for $15 \mathrm{~min}$, then washed with PBS followed by digesting for $15 \mathrm{~min}$ in proteinase $\mathrm{K}$. After being washed with PBS, sections were separately incubated with the Streptavidin-FITC $(100 \mu \mathrm{L})$ and DAPI $(100 \mu \mathrm{L})$ label solution in the dark for $1 \mathrm{~h}$ at $37^{\circ} \mathrm{C}$. The sections displaying green staining within the nucleus were counted as apoptotic cells under a fluorescence microscope.

\section{Hepatocytes culture}

Hepatocytes were isolated by a modification of the two-step collagenase perfusion method described by Zhang et al. (2012) [35]. Hepatocytes from the rat were grown in Dulbecco's modified Eagle's medium (DMEM) supplemented with $10 \% \mathrm{FBS}$, penicillin $(100 \mathrm{IU} / \mathrm{mL})$ and streptomycin $(100 \mathrm{mg} / \mathrm{mL})$ and maintained at $37^{\circ} \mathrm{C}$ in a humidified atmosphere in a $5 \% \mathrm{CO}_{2}$ incubator.

\section{Hepatocytes viability assay}

Hepatocytes viability was assessed by the cell counting kit-8 (CCK-8 kit, Beyotime biotechnology, China), according to standard protocols. Briefly, $5 \times 10^{4}$ hepatocytes were seeded in a 96-well plate containing DMEM supplemented with $10 \% \mathrm{FBS}$, grown at $37^{\circ} \mathrm{C}$ for $24 \mathrm{~h}$.

In vitro experiments, hepatocytes were divided into 4 groups: control, luteolin-treated $(20 \mu \mathrm{M}), \mathrm{HgCl}_{2}$-treated $(5 \mu \mathrm{M})$ and $\mathrm{HgCl}_{2}+$ luteolin-treated. Hepatocytes were preincubated with luteolin $24 \mathrm{~h}$ before $\mathrm{HgCl}_{2}$ administration. After that, the original medium was replaced by $100 \mu \mathrm{L}$ $10 \%$ FBS DMEM medium contain $10 \mu \mathrm{L}$ CCK-8 solution, followed by incubation at $37^{\circ} \mathrm{C}$ for $2 \mathrm{~h}$. The absorbance was finally determined at $450 \mathrm{~nm}$ with a microplate reader.

\section{Determination of intracellular levels of ROS}

Intracellular ROS levels were detected with a ROS assay kit (Beyotime biotechnology, China). DCFH-DA was deacetylated intracellularly by nonspecific esterase, which was further oxidized by ROS to the fluorescent compound 2,7-dichlorofluorescein (DCF). After treatment with $\mathrm{HgCl}_{2}$ and luteolin by means of hepatocytes viability assay, hepatocytes were pre-incubated with DCFH-DA at a concentration of $10 \mu \mathrm{M}$. After $20 \mathrm{~min}$, DCFH fluorescence was measured at an excitation wavelength of $488 \mathrm{~nm}$ and an emission wavelength of $525 \mathrm{~nm}$ with a Nikon TE2000 inverted microscope system.

\section{Real-time PCR analysis}

Total RNA was extracted from the frozen livers with Trizol reagent (Invitrogen, US). The total RNA concentration and purities were determined at $260 \mathrm{~nm}$. The target genes were quantified by SYBR ${ }^{\circledR}$ Premix $\mathrm{Ex} \mathrm{Taq}^{\mathrm{TM}}$ kit (Life Technologies, USA) according to the manufacturer's instructions. Using the $2^{-\Delta \Delta \mathrm{Ct}}$ method, the results were presented as the fold change in the target gene expression normalized to the endogenous reference gene ( $\beta$-action) and relative to the untreated control. The primer sequences used in this study were shown in the Table 2. 


\section{Western blot analysis}

Total protein concentration in the supernatant was determined with a bicinchoninic acid assay (Beyotime biotechnology, China). The equal amounts of protein were separated by SDS-PAGE on $8-12 \%$ Bis-Tris gels, transferred onto PVDF membranes. Primary antibodies against each protein were from Santa Cruz Biotechnology (Santa Cruz, CA, USA). Antibodies to GAPDH (Xianzhi, Hangzhou, China) were used as a standard control. The membrane was detected with the Imager Amersham 600 chemiluminescence system (General Electric Company, Fairfield, CT, USA).

\section{Determination of mercury accumulation in the liver}

Briefly, approximately $0.5 \mathrm{~g}$ liver tissues were digested with $\mathrm{HNO}_{3}-\mathrm{H}_{2} \mathrm{SO}_{4}$ solution. After aspiration and tomization of the sample, a light beam from a hollow cathode lamp was directed through the flame into a monochromator and onto a detector that measured the amount of light absorbed. The mercury content of liver tissues were analyzed by atomic fluorescence spectrometry (AFS-930; Beijing Jitian Instrument Company, Beijing, China).

\section{Statistical analysis}

Statistical analysis was performed by the SPSS 19.0 (SPSS, Chicago, IL, USA). All data were expressed as mean \pm SEM. The data in this report were evaluated by one-way ANOVA or Student's t Test. In all cases, $P<0.05$ were considered to be significant for comparison among different groups.

\section{Abbreviations}

ALT, alanine aminotransferase; AST, aspartate transaminase; Bax, Bcl-associated $\mathrm{X}$ protein; $\mathrm{Bcl}-2$, B-cell leukemia/lymphoma-2; Bcl-xL, Bcl-2-related protein long form of Bcl-x; DCF, 2,7-dichlorofluorescein; DMEM, dulbecco's modified Eagle's medium; DMPS, 2,3-dimercaptopropanesulfonic acid; DMSA, meso-2,3dimercaptosuccinic acid; FoxO3, forkhead box O3; GSH, reduced glutathione; GSSG, glutathione disulfide; H\&E, hematoxylin and eosin; $\mathrm{HgCl}_{2}$, mercuric chloride; $\mathrm{HO}-1$, Heme oxygenase-1; Lut, luteolin; $\mathrm{MCH}$, mean corpuscular hemoglobin; MCHC, mean corpuscular hemoglobin concentration; MCV, Mean corpuscular volume; MDA,

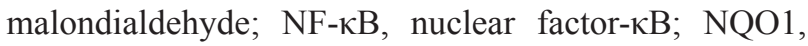
$\mathrm{NAD}(\mathrm{P}) \mathrm{H}$ quinone oxidoreductase $1 ; \mathrm{Nrf2}$, nuclear factorerythroid-2-related factor 2; $\mathrm{O}_{2}$, oxygen; ROS, reactive oxygen species; TNF- $\alpha$, tumor necrosis factor $\alpha$; TUNEL, terminal deoxynucleotidyl transferase-mediated dUTP nick end labeling;

\section{Authors' contributions}

HL Zhang and ZG Zhang designed and conducted experiments, and wrote the manuscript. HL Zhang, $\mathrm{X}$ Tan, DQ Yang, JJ Lu, BY Liu, and RQ Baiyun carried out the experiments and analyzed the data. All the authors contributed to and approved the final manuscript.

\section{CONFLICTS OF INTEREST}

The authors declare that there are no conflicts of interest.

\section{FUNDING}

This study was supported by the National Science Foundation Committee of China (31101868), the Program for New Century Excellent Talent in Heilongjiang Provincial University (1253-NCET-007), Scientific Research Foundation for Excellent Returned Scholars of Heilongjiang Province, University Nursing Program for Young Scholar with Creative Talents in Heilongjiang Province (UNPYSCT-2016012), and Academic Backbone Support Program (15XG17) to ZG Zhang approved by Northeast Agricultural University.

\section{REFERENCES}

1. Emsley J. Nature's building blocks:An A-Z guide to the elements. Oxford University Press. 2001.

2. Perottoni J, Lobato LP, Silveira A, Rocha JB, Emanuelli T. Effects of mercury and selenite on delta-aminolevulinate dehydratase activity and on selected oxidative stress parameters in rats. Environ Res. 2004; 95:166-73.

3. Moraes-Silva L, Bueno TM, Franciscato C, Oliveira CS, Peixoto NC, Pereira ME. Mercury chloride increases hepatic alanine aminotransferase and glucose 6-phosphatase activities in newborn rats in vivo. Cell Biol Int. 2012; 36:561-6.

4. Zhang J, Lu S, Wang H, Zheng Q. Protective role of Aralia elata polysaccharide on mercury(II)-induced cardiovascular oxidative injury in rats. Int J Biol Macromol. 2013; 59:301-4.

5. McFee RB, Caraccio TR. Intravenous mercury injection and ingestion:clinical manifestations and management. J Toxicol Clin Toxicol. 2001; 39:733-8.

6. FDA. Label and approval history. Drug: Chemet. 2007. http://www.accessdata.fda.gov/drugsatfda_docs/ label/2007/019998s013lbl.pdf.

7. Yu M, Xue J, Li Y, Zhang W, Ma D, Liu L, Zhang Z. Resveratrol protects against arsenic trioxide-induced nephrotoxicity by facilitating arsenic metabolism and decreasing oxidative stress. Arch Toxicol. 2013; 87:1025-35.

8. Wang X, Zhao H, Shao Y, Wang P, Wei Y, Zhang W, Jiang J, Chen Y, Zhang Z. Nephroprotective effect of astaxanthin 
against trivalent inorganic arsenic-induced renal injury in wistar rats. Nutr Res Pract. 2014; 8:46-53.

9. Zhang W, Xue J, Ge M, Yu M, Liu L, Zhang Z. Resveratrol attenuates hepatotoxicity of rats exposed to arsenic trioxide. Food Chem Toxicol. 2013; 51:87-92.

10. Farhat MB, Landoulsi A, Chaouch-Hamada R, Sotomayor JA, María JJ. Characterization and quantification of phenolic compounds and antioxidant properties of salvia species growing in different habitats. Indus Crops Prod. 2013; 49:904-14.

11. Navas-Lopez JF, Ostos-Garrido FJ, Castillo A, Martín A, Gimenez MJ, Pistón F. Phenolic content variability and its chromosome location in tritordeum. Front Plant Sci. 2014; $30 ; 5: 10$.

12. Iqbal E, Salim KA, Lim LB. Phytochemical screening, total phenolics and antioxidant activities of bark and leaf extracts of Goniothalamus velutinus (Airy Shaw) from Brunei Darussalam. J King Saud Univ Sci. 2015; 27:224-32.

13. Pandurangan AK, Dharmalingam P, Sadagopan SK, Ramar M, Munusamy A, Ganapasam S. Luteolin induces growth arrest in colon cancer cells through involvement of Wnt/ $\beta$-catenin/GSK-3 $\beta$ signaling. J Environ Pathol Toxicol Oncol. 2013; 32:131-9.

14. Cho JG, Song NY, Nam TG, Shrestha S, Park HJ, Lyu HN, Kim DO, Lee G, Woo YM, Jeong TS. Flavonoids from the grains of $\mathrm{C} 1 / \mathrm{R}-\mathrm{S}$ transgenic rice, the transgenic Oryza sativa spp. japonica, and their radical scavenging activities. J Agric Food Chem. 2013; 61:10354-9.

15. Jeon IH, Kim HS, Kang HJ, Lee HS, Jeong SI, Kim SJ, Jang SI. Anti-inflammatory and antipruritic effects of luteolin from perilla (P. frutescens L.) leaves. Molecules. 2014; 19:6941-51.

16. Ercis K, Aydoğan S, Atayoğlu AT, Silici S. Effect of propolis on erythrocyte rheology in experimental mercury intoxication in rats. Environ Sci Pollut Res. 2015; 22:12534-43.

17. Lehman-McKeeman L. Paracelsus and formaldehyde 2010:the dose to the target organ makes the poison. Toxicol Sci. 2010; 116:361-3.

18. Flora SJ, Mittal M, Mehta A. Heavy metal induced oxidative stress \& its possible reversal by chelation therapy. Indian J Med Res. 2008; 128:501-23.

19. Abdel-Moneim AE, Dkhil MA, Al-Quraishy S. The redox status in rats treated with flaxseed oil and lead-induced hepatotoxicity. Biol Trace Elem Res. 2011; 143:457-67.

20. Hinson JA, Roberts DW, James LP. Mechanisms of acetaminophen-induced liver necrosis. Handb Exp Pharmacol. 2010; 196:369-405.

21. Yao P, Chen X, Yan Y, Liu F, Zhang Y, Guo X, Xu B. Glutaredoxin 1, glutaredoxin 2, thioredoxin 1, and thioredoxin peroxidase 3 play important roles in antioxidant defense in Apis cerana cerana. Free Radic Biol Med. 2014; 68:335-46.
22. Yang YC, Lii CK, Lin AH, Yeh YW, Yao HT, Li CC, Liu KL, Chen HW. Induction of glutathione synthesis and heme oxygenase 1 by the flavonoids butein and phloretin is mediated through the ERK/Nrf2 pathway and protects against oxidative stress. Free Radic Biol Med. 2011; 51:2073-81.

23. Brown JM, Ball JG, Wright MS, Van Meter S, Valentovic MA. Novel protective mechanisms for S-adenosyl-L-methionine against acetaminophen hepatotoxicity:improvement of key antioxidant enzymatic function. Toxicol Lett. 2012; 212:320-8.

24. Kaya I, Karapehlivan M, Yilmaz M, Ersan Y, Koc E. Investigation of effects on plasma nitric oxide, malondialdehyde and total sialic acid levels of glyphosate in Kars creek transcaucasian barb (Capoeta capoeta [Guldenstaedt, 1773]) in Turkey. Fresenius Environ Bull. 2012; 21:123-6.

25. $\mathrm{Lu} \mathrm{SC}$. Glutathione synthesis. Biochem Biophys Acta. 2013; 1830:3143-53.

26. Ghosh M, Pal S, Sil PC. Taurine attenuates nano copper induced oxidative hepatic damage via mitochondria dependent and NF-kB/TNF- $\alpha$ mediated pathway. Toxicol Res. 2014; 3:474-86.

27. Abdel Moneim AE. Evaluating the potential role of pomegranate peel in aluminum-induced oxidative stress and histopathological alterations in brain of female rats. Biol Trace Elem Res. 2012; 150:328-36.

28. Green DR, Kroemer G. Cytoplasmic functions of the tumour suppressor p53. Nature. 2009; 458:1127-30.

29. Amaral JD, Xavier JM, Steer CJ, Rodrigues CM. The role of p53 in apoptosis. Discov Med. 2010; 9:145-52.

30. Cantó C, Auwerx J. AMP-activated protein kinase and its downstream transcriptional pathways. Cell Mol Life Sci. 2010; 67:3407-23.

31. Al-Anati L, Kadekar S, Högberg J, Stenius U. PCB153, TCDD and estradiol compromise the benzo $a$ ]pyreneinduced p53-response via FoxO3a. Chem Biol Interact. 2014; 219:159-67.

32. Wang A, Wang S, Jiang Y, Chen M, Wang Y, Lin L. Bioassay guided identification of hepatoprotective polyphenols from Penthorum chinense Pursh on t-BHP induced oxidative stress injured L02 cells. Food Funct. 2016; 7:2074-83.

33. Ray PD, Huang BW, Tsuji Y. Reactive oxygen species (ROS) homeostasis and redox regulation in cellular signaling. Cell Signal. 2012; 24:981-90.

34. Taguchi K, Motohashi H, Yamamoto M. Molecular mechanisms of the Keap1-Nrf2 pathway in stress response and cancer evolution. Genes Cells. 2011; 16:123-40.

35. Zhang L, Zhang H, Miao Y, Wu S, Ye H, Yuan Y. Protective effect of allicin against acrylamide-induced hepatocyte damage in vitro and in vivo. Food Chem Toxicol. 2012; 50:3306-12. 